\title{
THE EFFECT OF INTRAOPERATIVE DEXMETOMIDINE ON ACUTE POSTOPERATIVE PAIN AFTER TOTAL KNEE REPLACEMENT: A RANDOMIZED CONTROLLED TRIAL
}

\section{Diagoupi ${ }^{1}$, M. Diakomi1, E. Stavropoulou1, I. Ntrimeri', A. Bairaktari1, A. Sofianou1 General Hospital of Attica "KAT", Anesthesiology Department, Athens, Greece.}

\section{Background and aims}

Total knee replacement has been associated with poor pain resolution despite current pain control regimens.

Dexmetomidine is a selective alpha ${ }_{2}$-adrenergic agent with sedative and analgesic properties, which has been used to enhance both central and peripheral nerve blockade. This prospective randomized trial was conducted to examine the effect of intraoperative dexmetomidine on postoperative analgesia after total knee arthroplasty.
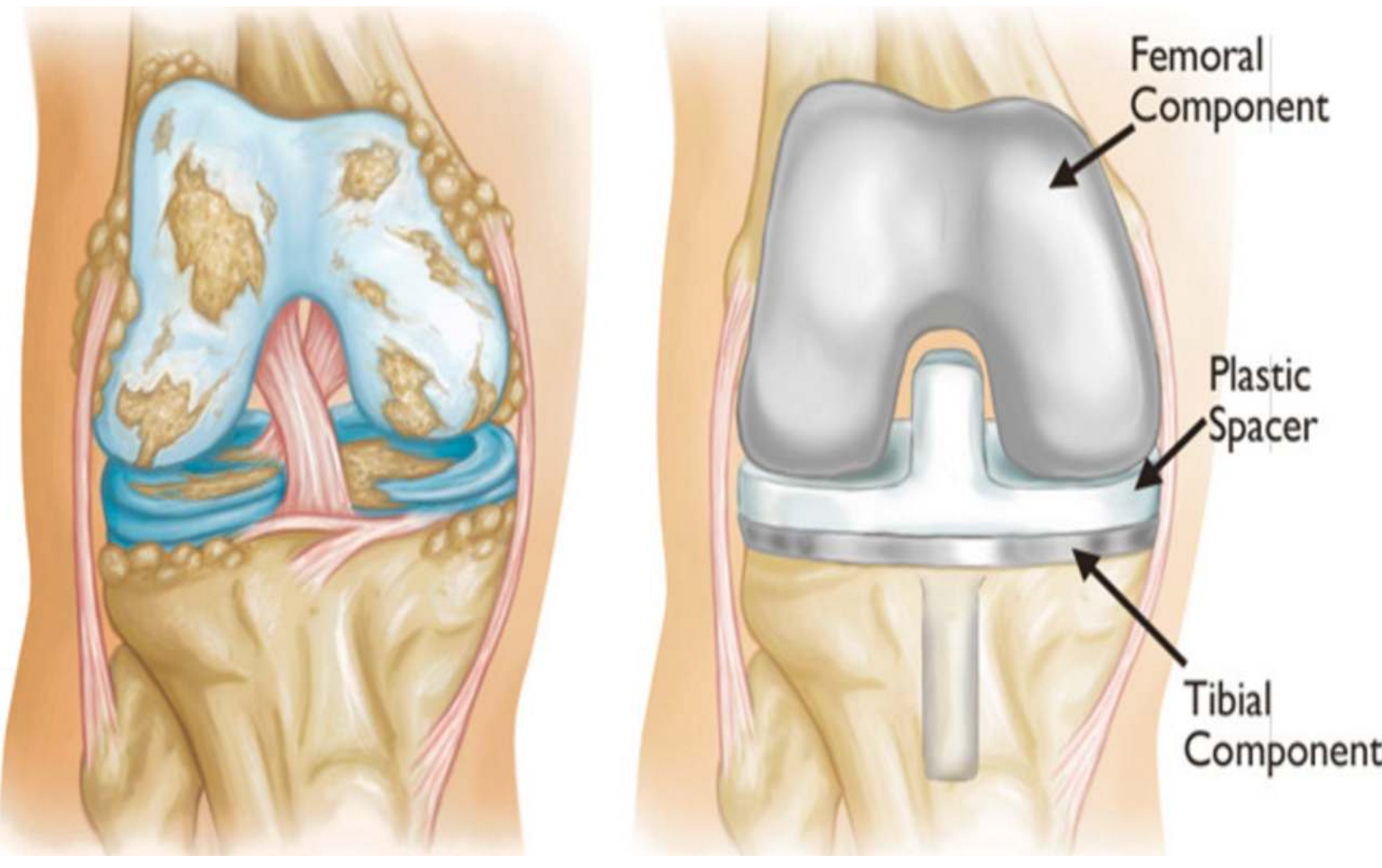

\section{Methods}

51 patients scheduled for total knee replacement

(TNR) were randomized to receive spinal

levobupivacaine (control group), spinal

levobupivacaine and dexmetomidine (SubDEX group) or spinal levobupivacaine and intravenous dexmetomidine infusion (IvDEX group). Visual Analog Scale (VAS) pain scores at 3, 6 and 12 postoperative hours and side effects were recorded. Patients reporting VAS $\geq 3$ received a standard rescue analgesia-regimen.

\section{Results}

Patients of SubDEX group showed significantly lower VAS scores at 3 hours postoperatively compared to control group $(p<0,004)$, while patients of IVDEX group failed to demonstrate such an effect. SubDEX group also presented with lower VAS scores at 6 and 12 hours post -surgery when compared to IVDEX group, but the differences were not significant.

Time to initiation of rescue analgesia was significantly higher in SubDEX group (285 $\pm 109 \mathrm{~min})$ compared to

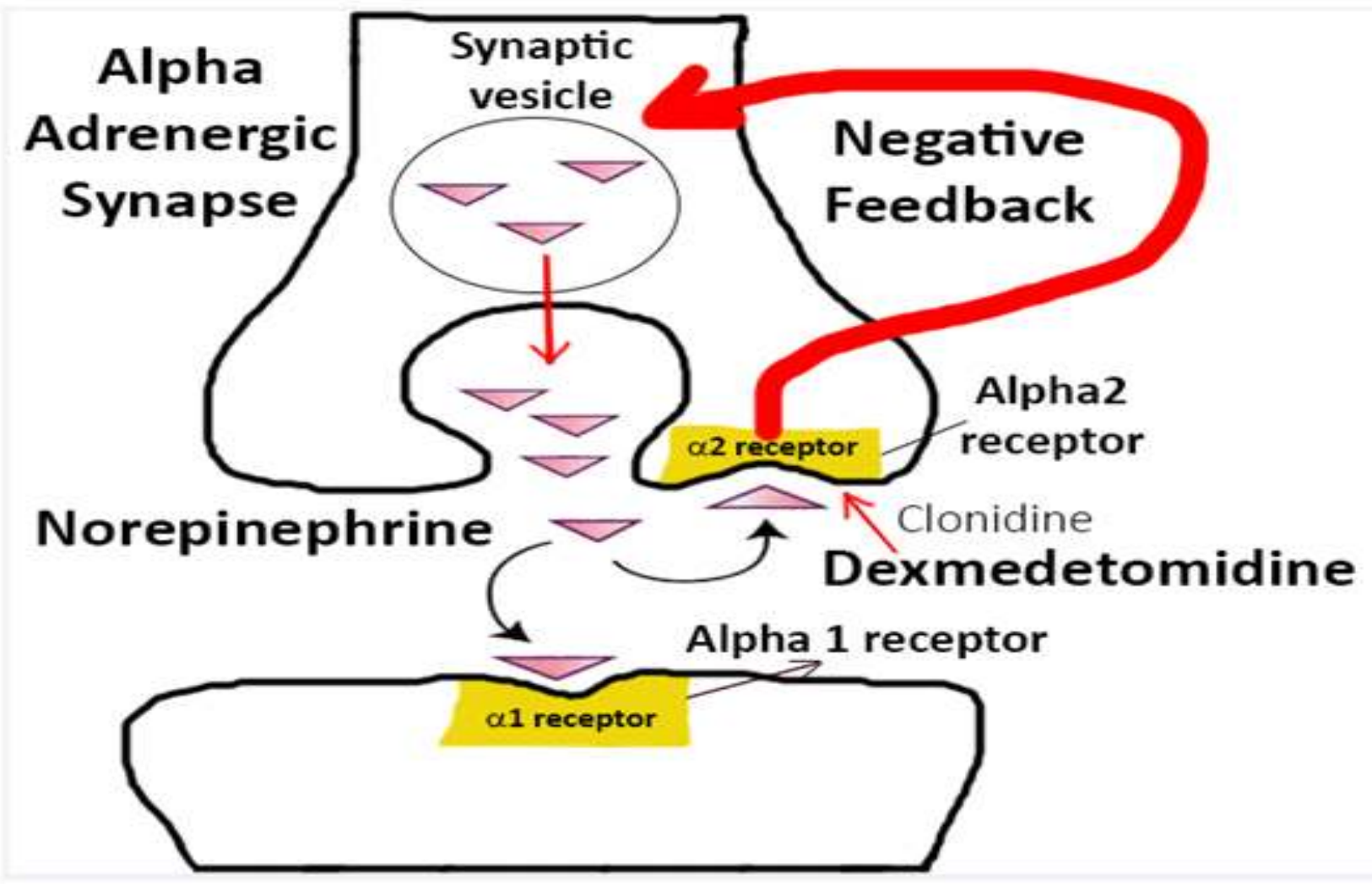

IVDEX (220 $\pm 97 \mathrm{~min})$ and control group (146 $\pm 58 \mathrm{~min})$. All groups demonstrated a safe hemodynamic profile. No adverse effects were reported.

\section{Conclusions}

Subarachnoid dexmetomidine provided safe and superior postoperative analgesia at 3 hours after TNR as an adjuvant in a multimodal pain regimen. Further research is required to provide high quality evidence in favor of subarachnoid dexmetomidine as a part of an effective multimodal strategy for pain control after TNR. 